\title{
The Relationship between Language Learning Motivation and the Choice of Language Learning Strategies among Chinese Graduates
}

\author{
Xiuyan Xu \\ School of Foreign Language, China Geo-Sciences University (Beijing) \\ 29 Xue Yuan Road, Beijing 100083, China \\ E-mail: zijingmum@hotmail.com
}

Received: March 15, 2011 Accepted: March 30, 2011 doi:10.5539/ijel.v1n2p203

The research is financed by the Department of Science\& Technology of China Geo-Science University. No. 200711

\begin{abstract}
This research is aimed to investigate the relationship between language learning motivation and the choice of language learning strategies among Chinese graduates of non-English majors. A total of 300 graduates participated in this survey research and 284 subject responses were valid and used for the statistical analysis. The collected data were computed and analyzed through descriptive statistics, test of normality, test of linearity and Pearson correlation. The major findings of the study were: (1) Chinese graduates tended to be more extrinsically motivated. (2) Their motivation was found significantly correlated with their learning strategy use. The more motivated students were the more strategies they tended to use. (3) Motivational strength and personal goals were found to have the highest correlation with the overall strategy use among Chinese graduates.
\end{abstract}

Keywords: Learning motivation, Language learning strategies, Personal goals, Motivational strength, Intrinsic motivation, Extrinsic motivation

\section{Introduction}

According to Gardner, research in language learning strategies suggested that several factors could influence strategy use, however, motivation is regarded as the most important one (1985). Accordingly, an increasing number of L2/FL researchers indicated that both learning motivation and learning strategies play important roles in successful language learning, which suggest a need to investigate the links between two significant characteristics of learning (Ellis, 1994).

So far, numbers of research proved the close relationship between language learning motivation and learning strategies (Ellis, 1994; Wen, 2004). However, no well-established theories directly indicated the exact relationship between language learning motivation and learning strategies (Zhang \& Guo, 2001). Besides, previous studies on Chinese students' English learning motivation mostly followed the classical social educational model proposed by Gardner (Gao, Cheng, Zhao \& Zhou, 2003a), and until now, no researchers were found to use Schmidt's motivational questionnaire to examine the relationship between motivation and learning strategies in Chinese EFL context. Furthermore, limited research is conducted in dealing with Chinese graduates on their learning motivation and learning strategies. Consequently, more academic research should be conducted on the relationship between language learning motivation and learning strategies among Chinese graduates.

The purpose of the current study is to investigate the relationship between language learning motivation and the choice of language learning strategies among Chinese graduates. The major orientation for this study was not to examine motivation in isolation but to explore the links between motivation and learning strategies. Looking for links between motivation and learning strategies is motivated by a concern with how motivation works. Basic assumption of the study is that motivated learners learn more because they seek out input, interaction, and instruction, and when they encounter target language input they pay attention to it and actively process it however they can (Schmidt \& Watanabe, 2001).

Specifically, the study focuses on the following research questions:

1) What are Chinese graduates' language learning motivations?

2) What are Chinese graduates' learning strategies?

3) Is there a relationship between language learning motivation and language learning strategies?

4) What is the relationship among the scales of motivation and those of language learning strategies? 


\section{Literature Review on Language Learning Motivation and Language Learning Strategies}

\subsection{On Language Learning Motivation}

Motivation would probably be identified as the most powerful influences on learning to most teachers. SLA research also views motivation as a key factor in L2/FL learning. Brown (1994) gave the definition of motivation as "the extent to which you make choices about (a) a goal to pursue and (b) the effort you will devote to the pursuit". Relating motivation to learn a second language (L2), Gardner (1985) proposed, "Motivation is a term which is often used with respect to second language learning as a simple explanation of achievement". Gardner's (1985) definition of motivation in language learning was the "effort plus desire to achieve the goal of learning the language plus favorable attitudes toward learning the language".

There are also literally dozens of complementary theories of motivation in psychology. From the behavioristic psychologists' perspectives, the role of drive and reinforcement are emphasized, and motivation is defined as "the anticipation of reinforcement" (Brown, 1994). Beginning in the 1990s, there was a transformation of defining motivation as a more dynamic and cognitive term (Vandergrift, 2005). Cognitive view of motivation centers on individual making decisions about their own actions as opposed to being at the mercy of external factors over which they have no control (Williams \& Burden, 1997). Social constructivists stressed motivation as a state of cognitive and emotional arousal which leads to a conscious decision to act, and which gives rise to a period of sustained intellectual and/or physical effort in order to attain a previously set goal (or goals) (Williams \& Burden, 1997).

One of the dominant frameworks in the contemporary psychological theories is Deci and Ryan's (1985) self-determination theory. The intrinsic and extrinsic motivations were interpreted in the self-determination theory. Deci and Ryan (1985) stated that intrinsic motivation is involved in doing something that it is inherently interesting or pleasure and extrinsic motivation refers to doing something because it leads to a separate outcome. Self-determination is regarded as a prerequisite for any behavior to be intrinsically rewarding. As Williams and Burden (1997) indicated, "one of the most general and well-known distinctions in motivation theories is that of intrinsic versus extrinsic motivation".

Considering the wide variety of factors that might be expected to influence motivation for foreign language learning, Schmidt, on the article "Foreign Language Motivation: Internal Structure and External Connections", explored the concept of foreign language motivation within a broad conception of motivation that avoids premature reductionism or assumes that all aspects of motivation are universal (Schmidt et al., 1996). The model of motivation used was a composite of several current models, especially those of Pintrich (1989), deCharms (1968), Keller (1983), Maehr and Archer (1987), and Dornyei (1990). These models fall generally within the broad category of value-expectancy theories of motivation. Such models assume that motivation is a multiplicative function of values and expectations. People will approach activities that they consider valuable and relevant to their personal goals and that they expect to succeed at (Schmidt et al., 1996).

\subsection{On Language Learning Strategies}

Oxford (1990) stated that strategies are particularly important for language learning "because they are tools for active, self-directed involvement, which is essential for developing communicative competence". Because of its significance, learning strategies have been extensively employed in the educational field. In defining the language learning strategy, Oxford \& Crookall (1989) stated that "different researchers use different terms and different concepts".

Rubin (1987) proposed, "Language learning strategies are strategies which contribute to the development of the language system which the learner constructs and affect learning directly. She also suggested that language learning strategies include "any set of operations, steps, plans, routines used by the learner to facilitate the obtaining, storage, retrieval and use of information". Chamot (1987) gave a definition of language learning strategies as "techniques, approaches or deliberate actions that students take in order to facilitate the learning and recall of both linguistic and content area information". She proposed that some language learning strategies are observable, but some may not be observable. In cognitive perspective, O'Malley and Chamot (1990) viewed language learning strategies as "the special thoughts behaviors of processing information that individuals use to help them comprehend, learn, or retain new information". Oxford (1990) claimed "learning strategies are steps taken by students to enhance their own learning". She proposed a more specific definition of learning strategies as "specific actions taken by the learner to make learning easier, faster, more enjoyable, more self-directed, more effective, and more transferable to new situations". Ellis (1994) sought to define learning strategies by listing the main characteristics of learning strategies.

\subsection{Research into the Relationships between Learners' Motivation and Language Learning Strategies}

According to Dornyei (2003), learning strategies are techniques that students apply of their own will to enhance the effectiveness of their learning. In this way, strategy use constitutes the factors of motivated learning behavior. 
'Motivation is a necessary component of strategic behavior and a precursor to strategy use (Weinstein, C et al., 1988).' The systematic study of the relationship between L2 motivation and language learning strategy started in the mid-1990s by Richard Schmidt, Peter MacIntyre, and their colleagues (Dornyei, 2003). Later on, many further study and SLA related research have identified the significant relationship between strategy use and motivation. Dornyei and Csizer (2005) argue that motivation is only indirectly related to learning achievement, because motivation is a concept that explains why people behave as they do rather than how successful their behavior will be. Motivation has been always considered as a critical factor affecting strategy choice (Ellis, 1994; Wen \& Wang, 2004). 'The type of motivation may also influence strategy choice (Ellis, 1994).'

'The strength of learners' motivation can be expected to have a causal effect on the quantity of learning strategies they employ (Ellis, 1994).' Highly motivated learners use more appropriate strategies than those less motivated learners. Both language learning motivation and strategy are closely related to the goal of language learning (Oxford, 1990). Effective use of learning strategies may sustain motivation in language (Vandergrift, 2005)

Oxford and Nyikos in a study of students of foreign languages in universities in the United States found that 'the degree of expressed motivation was the single most powerful influence on the choice of language learning strategies (Ellis, 1994).'

Schmidt et al. (1996) probed EFL learning in Egypt. They found that EFL learners with high expectancy and strong instrumental motivation attempted to use active cognitive strategies and organizing strategies. They also reported that anxiety is not significantly associated with any set of learning strategies.

Schmidt and Watanabe (2001) conducted an investigation on motivation and strategy use among 2,089 learners of five different foreign languages at the University of Hawaii. They reported that not all aspects of motivation affect strategy use equally, and not all strategies are equally affected by motivational factors. The study further showed that motivational strength emerged as the strongest predictor of the use of language learning strategies. Among the different types of learning strategies, the uses of cognitive and metacognitive strategies were most affected by motivation.

In China, only a few studies have focused on the issue of Chinese EFL learners' motivation and language learning strategy use. Wen reported a study on developmental patterns of modifiable learner variables (i.e. motivation, beliefs and strategies) and their relations based on longitudinal questionnaire data. The research results indicate that the relationships among the variables such as motivation, beliefs and strategies are fairly stable. (2001).

Ge (2006), according to the questionnaire and research conducted by Wen (2001), investigated the developmental patterns of modifiable learner variables (i.e. motivation, beliefs and strategies) for middle school students. The result indicated that motivation and beliefs had strong influence on the choice of learning strategies.

Qin and Wen (2002), in conducting the research concerning the internal structures of language learning motivation of non-English majors, propose the internal motivation structure and find that causal attribution, defined as the combination of intellectual and physical effort and language learning strategies, will have direct and active influence on motivational performance.

Luo, Jian and Wang (2004) distributed questionnaires to 455 undergraduates to testify the relationship between motivation, language learning strategies and the final study score. They reported that motivation had a strong correlationship with language learning strategies. Students' learning motivation had a strong influence on the study score. Intrinsic motivation, integrative motivation had positive relationship with learning outcome, while extrinsic motivation had negative relationship.

Although many scholars have realized the importance of language learning motivation and its influence on language learning strategies, it is also important to note that very few samples of the studies are about Chinese graduates. The present study seeks to explore the correlation between language learning motivation and the choice of language learning strategies among them.

\section{Methodology}

\subsection{Subjects}

The targeted population of this research was Chinese graduates. The questionnaires were distributed among graduates of non-English majors from China Geo-Science University (Beijing). The reason for only choosing graduates of non-English majors is that their use of English learning strategies will be quite different from English majors'. The ages of participants are from 23-25. They have learned English for more than 10 years. A total of 300 graduates were invited to participate in this survey research in 2009. Among all the participants, 235 were male students which occupied almost $83 \%$ of all participants. Of the 300 returned questionnaires, 16 questionnaires were discarded as invalid, those either incomplete or did not follow the answering instruction. Therefore, a total of 284 subject responses (94.7\% of 300 participants) were used for the statistical analysis. 


\subsection{Instrument}

The survey instruments of this study involved two sets of questionnaires: (a) Motivational Questionnaire, and (b) Strategy Inventory for Language Learning (SILL). To assess if the items in the questionnaires provide accurate assessment of language learning motivation and language learning strategies, the current research questionnaires were subjected to Cronbach's Alpha Internal Consistency Reliability, and the results supported the internal consistency of the questionnaire and guaranteed that the questionnaire could be used in this study.

\section{Results}

\subsection{What are the language learning motivation of Chinese graduates?}

Descriptive statistics were used to understand the language learning motivation in terms of different variables in the Motivational Questionnaire among Chinese graduates. As shown in Table 1, the mean of intrinsic motivation was 3.92. Approximately $19.7 \%(\mathrm{n}=56)$ of subjects were in a low to medium degree of intrinsic motivation, and $80.3 \%(\mathrm{n}=228)$ of subjects were in a medium to high degree of intrinsic motivation. The mean of extrinsic motivation was 4.53 . Approximately $3.2 \%(\mathrm{n}=9)$ of subjects were in a low to medium degree of extrinsic motivation, and $96.8 \%(\mathrm{n}=275)$ were in a medium to high degree of extrinsic motivation. The mean of personal goals was 4.59 . Approximately $2.8 \%(\mathrm{n}=8)$ of subjects were in a low to medium degree of personal goals, and $97.2 \%(\mathrm{n}=276)$ were in a medium to high degree of personal goals. The mean of expectancy was 3.62. Approximately $11.6 \%(n=33)$ of subjects were in a low to medium degree of expectancy, and $88.4 \%(n=251)$ were in a medium to high degree of expectancy. The mean of attitudes was 3.92 . Approximately $12 \%(n=34)$ of subjects were in a low to medium degree of attitudes, and $88 \%(\mathrm{n}=250)$ were in a medium to high degree of attitudes. The mean of anxiety was 3.04 . Approximately $52.1 \%(\mathrm{n}=148)$ of subjects were in a low to medium degree of anxiety, and $47.9 \%(\mathrm{n}=136)$ were in a medium to high degree of anxiety. The mean of motivational strength was 4.53 . Approximately $3.5 \%(\mathrm{n}=10)$ of subjects were in a low to medium degree of motivational strength, and $96.5 \%(\mathrm{n}=274)$ were in a medium to high degree of motivational strength.

Since the highest score in the rating was six and the lowest score was one, the results indicate that anxiety $($ mean $=3.04)$ was at a lower degree; expectancy (mean=3.62) was at a medium degree; intrinsic motivation (mean=3.92) and attitudes (mean=3.92) were at a higher degree than the medium level; extrinsic motivation (mean=4.53), personal goals (mean=4.59), and motivational strength (mean=4.53) were at a moderately high degree. Accordingly, Chinese graduates of tended to be more extrinsically motivated with their definite personal goals and strong motivational strength; they also have moderate degree of intrinsic motivation, while they have a comparatively low degree of learning anxiety.

\subsection{What are Chinese graduates'learning strategies?}

Descriptive statistics were employed to investigate the language learning strategies that Chinese graduates are using. Table 2 illustrates that the mean of frequency of overall strategy use was 4.3 , which was approximately at a higher level (with a range from 1 to 6). According to the results of Table 2, the most frequently used strategy was metacognitive strategies (mean $=4.52$ ), followed by compensation strategies $(m e a n=4.45)$, cognitive strategies (mean=4.36), social strategies (mean $=4.33$ ) and memory strategies (mean=3.98). There was not a big difference among the frequency of each strategy that Chinese graduates use.

\subsection{The Relationship between Language Learning Motivation and Language learning Strategies}

Before Pearson Correlation Coefficient is conducted, the normality of variables and the linearity of the relationship between the two variables need to be ensured.

Both Kolmogorov-Smirnov and Shapiro-Wilk tests were conducted testing whether the "motivation" and "strategy" are normally distributed. Due to the limited sample size, it is necessary to refer to the W statistic under Shapiro-Wilk (in Table 5), which is .993 and .992 . The significance is .248 and .110, which are $>.05$, indicating that there is not a significant difference between the "motivation" variable distribution and normal distribution and there is not a significant difference between the "strategy" variable distribution and normal distribution. It is now safe to say that the "motivation" variable distribution is normal and the "strategy" variable distribution is normal.

The scatterplot (graph1) shows that the dots are staying around the straight line. Experience will show that the relationship between "motivation" and "strategy" is linear. Besides, an ANOVA table (Table 7) was computed to obtain an exact result of the linearity of the relationship between "motivation" and "strategy". The significance of linearity is .000 , which is $<.05$, indicating that the relationship between "motivation" and "strategy" is linear.

The result of the above testing of normality and linearity shows that the variables in this research is normally distributed and the relationship between two interested variables is linear, which allow for the computation of correlation study.

Pearson product-moment correlation was computed to examine the relationships between learning motivation 
and language learning strategy use.

As the result of Pearson product moment correlation analysis in Table 9 shows, language learning motivation is significantly and positively correlated with overall language learning strategy use $(r=.459, \mathrm{p}<.05)$. The more motivated students are, the more strategies they tend to use.

\subsection{The Relationship among the Scales of Motivation and Those of Language Learning Strategies}

Pearson product-moment correlation was computed to examine how these learning motivation and language learning strategy use related to each other.

In the field of statistics, $r \leq .20$ would be considered as low degree of correlation and usually will not be calculated into the study; $\pm 0.20 \sim \pm 0.40$ would be considered as significantly correlated; $\pm 0.40 \sim \pm 0.70$ would be considered as moderately significant correlation; $\pm 0.70 \sim \pm 0.90$ would be considered as highly significantly correlated (Qin, 2003).

As the results of Pearson product moment correlation analysis in Table 10 indicate, intrinsic motivation was positively correlated with the use of memory strategies, compensation strategies $(r=.191, .137, \mathrm{p}<.05)$ at low degree, and significantly correlated with the use of cognitive strategies metacognitive strategies and social strategies $(\mathrm{r}=.291, .326, .204, \mathrm{p}<.05)$.

Similarly, extrinsic motivation was positively correlated with the use of memory strategies, cognitive strategies, metacognitive strategies, affective strategies and social strategies $(\mathrm{r}=.182, .144, .185, .184, .193, \mathrm{p}<.05)$ at low degree.

Expectancy was positively correlated with the use of memory strategies, cognitive strategies, metacognitive strategies and affective strategies $(\mathrm{r}=.272, .182, .162, .243, \mathrm{p}<.05)$.

Anxiety was negatively correlated with the use of cognitive strategies, metacognitive strategies and social strategies $(\mathrm{r}=-.294,-.170,-.178, \mathrm{p}<.05)$.

Personal goals, attitudes and motivational strength were positively correlated with the overall types of learning strategies: memory strategies, $(\mathrm{r}=.361, .329, .383, \mathrm{p}<.05)$, cognitive strategies $(\mathrm{r}=.342, .376, .420, \mathrm{p}<.05)$, compensation strategies $(\mathrm{r}=.238, .275, .224, \mathrm{p}<.05)$, metacognitive strategies $(\mathrm{r}=.391, .322, .493, \mathrm{p}<.05)$, affective strategies $(\mathrm{r}=.252, .195, .252, \mathrm{p}<.05)$ and social strategies $(\mathrm{r}=.328, .263, .314, \mathrm{p}<.05)$. Motivational strength was moderately significantly correlated with cognitive strategy $(\mathrm{r}=.420, \mathrm{p}<.05)$, and metacognitive strategies $(\mathrm{r}=.493, \mathrm{p}<.05)$.

Besides, among learning motivation, motivational strength and personal goals had comparatively higher correlation with memory, cognitive, compensation, metacognitive, affective and social strategies. Extrinsic motivation had lowest correlation with memory, cognitive, compensation, metacognitive and social strategies and had comparatively lower degree of correlation with affective strategies.

Furthermore, all motivational variables in the study had significant correlation with overall strategy use, among which motivational strength and personal goals had highest correlation with overall strategy use $(\mathrm{r}=.484, .430$, $\mathrm{p}<.05)$. Besides, anxiety was correlated with overall strategy use at a low level $(\mathrm{r}=-.185<-.2, \mathrm{p}<.05)$.

\section{Discussion}

Tables (1-10) present the results obtained when the data collected were analyzed. The results from this current study showed that motivation seemed to have a direct influence in the use of language learning strategies, which is in line with the findings in other research studies (Ehrman \& Oxford, 1989; Oxford \& Nyikos, 1989).

The results indicated that Chinese graduates tended to have higher extrinsic motivation, personal goals and motivational strength. They also have a moderate degree of intrinsic motivation, while they have a comparatively low degree of learning anxiety. The possible explanation for the result of the present study is that most Chinese students learn English only because that an English diploma could assist them to obtain a good job. Graduates tend to be more proficient in learning English than undergraduates, and sufficient exposure to English and intensive English training could provide them many opportunities to be familiar with western culture which arouses their strong interest in English learning, meanwhile, after two-year of oral English practice, graduates tend to be more confident when communicate with others in English, and in turn build their confidence. Therefore, they show a low degree of learning anxiety.

Chinese graduates' learning motivation was also found significantly correlated with strategy use as significant difference at $\mathrm{p}<.05$ level was found. This study also showed that not all aspects of motivation affect strategy are used equally, and not all strategies are equally affected by motivational factors. The findings of this present research are in accordance with the result of Schmidt \& Watanabe(2001).

In the present survey, motivational strength and personal goals were found to have highest correlation with overall strategy use. The finding of this study is somewhat similar to the results of Schmidt's (2001) study. The 
result shows that the strongest predictor of strategy use among the motivational scales is Motivational Strength. Yang argued that greater strength of motivation corresponded with more frequent use of strategies (Chang Chaing-yi, 2003). In the process of learning, Chinese students would probably make full use of all strategies suitable to them. Besides, a specific and achievable goal could positively influence their motivational strength and hence influence the choice of learning strategies. Furthermore, it is clear from table 9 that the strategies which mostly affect motivation are those in our scales of cognitive and metacognitive strategies, followed by affective and memory strategies. The finding of this study is somewhat similar to the results of Schmidt's (2001) study. The result shows that cognitive and metacognitive strategies are the types of strategies which are mostly affected by motivation. Besides, learners possibly prefer memory strategies because they believe that memory strategies are effective and convenient, and rely on affective strategies to make themselves relax and control their emotions in their language learning.

Since the result of the study reported that language learning motivation is significantly correlated with the use of language learning strategies, and both are significant for achieving better foreign language. Therefore, an English teacher should understand more about students' motivation and strategy use in order to assist students to achieve better results in language learning.

Based on the results of current research, all motivational factors tended to be important factors in successful language learning. Perhaps, some general suggestions for instructors and educators are as follows:

Firstly, teachers could reinforce students' extrinsic motivation. As the result of the study indicates, Chinese graduates' learning motivation tended to be more extrinsically motivated. Behaviorism shows that reinforcer is any consequence that strengthens the behavior it follows. Teachers could positively reinforce students to become active participants by the employment of different kinds of teaching methods and be responsible for their own learning through setting reasonable but challenging goals in order to enhance their extrinsic motivation.

Secondly, teachers could assist students to make a goal suitable for them, enhancing their motivational strength and help them hold positive attitudes towards English learning. This study shows that personal goal and motivational strength are two important factors for students to choose certain learning strategies. Thus, English teachers should help learners to establish proper and specific short-term goals which are achievable for them. Through achieving these short-terms goals, their confidence and motivation can be greatly increased, which will motivate them to reach their long-term goals. Besides, Teachers may give constant feedback on students' progress, assist them to put their best efforts into learning the language and encourage them to have positive attitudes toward errors and failure during the process of language learning.

Thirdly, teachers could establish intrinsic reward system and employ various teaching methods. Although, Chinese graduates are more extrinsically motivated rather than intrinsically motivated, intrinsic motivation is more closely associated with overall strategy use compared with extrinsic motivation. Therefore, intrinsic motivation should be encouraged. Teachers can assist learners to create their own intrinsic reward system through utilization of existing needs. Students came to classes with different needs; therefore, teachers can help students identify their needs and assist them in finding self-fulfillment during the process of learning. Besides, teachers should employ as many varied teaching methods as possible with EFL learners. Schmidt et al. (1996) asserted that students' interest could be enhanced "by using varied materials, by starting lessons with questions that put the learner into a problem-solving mode, by relating instructional material to topics already of interest to learners, and by the use of paradoxes and puzzles".

Furthermore, teachers could try their best to minimize the degree of anxiety of students. Anxiety is a very important psychological factor for Chinese students to learn English. Teachers could make a welcoming and positive classroom for EFL learners where psychological needs are met and where language anxiety is kept to a minimum (Oxford \& Shearin, 1996).

Finally, EFL teachers should cultivate and raise their awareness of language learning strategies. According to the results of this study, some students indicated that they do not really use these strategies for their English learning even though they know the strategies are available. Consequently, it is very crucial for students to understand the importance of using language learning strategies in the process of language learning. Once students are aware of the advantages of using strategies in their language learning process, they will be willing to and appropriately employ these strategies to facilitate their English learning.

\section{Future Research and Limitations of the Study}

It is suggested that researchers consider the following recommendations for further research.

a. In the current study, the researcher employed the Motivational Questionnaire and the Strategy Inventory for Language Learning (SILL) as the instruments to obtain data and perform the statistical analyses. However, every individual instrument has its strengths and weaknesses, hence, some other instruments could be taken into consideration for further relevant study. The survey technique was the only method 
adopted to investigate the language learning motivation and language learning strategy use in this present study, but there are still various research methods such as interviews, classroom observations, diary analyses and experimental design which could be used to obtain more information and may help reduce the bias caused by using a single research method.

b. In future research, it is recommended to adopt both quantitative and qualitative analyses in the research. These two kinds of research methods could mutually support each other in order to take broad and clear views of language learning process.

c. In this current research, the effects of language learning motivation on the use of language learning strategies were examined, however, there are still various factors influencing strategies use. Therefore, the effects of other affective factors such as attitudes, anxiety, and learners' belief about their English learning should be examined in the future research.

This study has a comparatively small sample size. The participants of this study were limited at only one university in Beijing. The number of subjects was limited to students who voluntarily participated in answering and completing the questionnaires.

The instruments used in this study, the Strategy Inventory for Language Learning (SILL) and Motivational Questionnaire, are not the only instruments for investigating motivation and the strategy use, although they are commonly used by many researchers. Therefore, the SILL and Motivational Questionnaire may not cover all motivational variables and the effective language learning strategies FL learners use.

Besides, it is hard to guarantee that students could finish the questionnaire honestly, which may affect the accuracy of data information, and will hence influence the result of the experiment, although the researcher had tried her best.

Furthermore, it is better to use a combination of quantitative and qualitative research method in further study although only quantitative analyses were employed in this survey research.

\section{References}

Brown, H. D. (1994). Teaching by principles: An interactive approach to language pedagogy. NJ: Prentice Hall Regents.

Chamot, A. (1987). 'The learning strategies of ESL students' in Wenden and Rubin.

Chang, Ching-yi. (2003). The Effects of Language Learning Motivation on the Use of Language Learning strategies Among EFL Learners at Technological Universities and Colleges in Taiwan. Unpublished doctor's thesis, Spalding University, US.

Deci, E.L., \& Ryan, R.M. (1985). Intrinsic motivation and self-determination in human behavior. New York, NY: Plenum Press.

Dornyei, Z. (1998). Motivation in second and foreign language learning. Language Teaching, 31, 117-35. doi:10.1017/S026144480001315X, http://dx.doi.org/10.1017/S026144480001315X

Dornyei, Z. (2003). Attitudes, Orientation, and Motivations in Language Learning: Advances in Theory, Research, and Applications. Language Learning, 1, 3-32. doi:10.1111/1467-9922.53222, http://dx.doi.org/10.1111/1467-9922.53222

Ellis, R. (1994). The Study of Second Language Acquisition. Oxford: Oxford University Press.

Gao, Yihong, Zhao, Yuan, Cheng, Ying \&Zhou, Yan. (2003a). Motivation Types of Chinese College Undergraduates. Modern Foreign Languages, 26, 28-38.

Gardner, R.C. (1985). Social Psychology and Second Language Learning: The Role of Attitudes and Motivation. London: Edward Arnold.

Keller, J.M. (1983). Motivational design of instruction. In C.M.Reigeluth (Ed.), Instructional design theories and models (pp.386-433). Hillsdale, NJ: Erlbaum.

Luo, Jiawen \& Jian, Xiaoming. (2004). Research on Relationships among Learning Motivation, Foreign Language Learning Strategies and Academic Achievement. Research in Teaching, 27, 149-151.

O'Malley, J. \& A.Chamot. (1990). Learning strategies in Second Language Acquisition. Cambridge: Cambridge University Press.

Oxford, R. \& Shearin, J. (1996). Language learning motivation in a new key. In R.L.Oxford (Ed.), Language learning motivation: Pathways to the new century (pp.121-144). Hawaii: University of Hawaii Press.

Oxford, R. (1990). Language Learning Strategies: what every teacher should know. New York: Newbury House. Oxford, R.L., \& Crookall, D. (1989). Research on language learning strategies: Methods, findings, and instructional issues. Modern Language Journal, 73, 404-19. doi:10.2307/326876, http://dx.doi.org/10.2307/326876 
Qin, Xiaoqing \& Wen, Qiufang. (2002). Internal Structure of EFL Motivation at the Tertiary Level in China. Foreign Language Teaching and Research, 34, 51-58.

Qin, Xiaoqing. (2003). Quantative Analysis in Foreign Language Teaching and Research. Wuhan: Huazhong University of Science and Technology Press.

Schmidt, R. \& Watanabe, Y. (2001). Motivation, strategy use, and pedagogical preferences in foreign language learning. In Dornyei, Z \& Schmidt, R (Eds.), Motivation and Second Language Acquisition, (pp. 313-360). Hawaii: University of Hawaii Press.

Schmidt, R., Boraie, D., \& K assabgy, O. (1996). Foreign language motivation: Internal structure and external connections. In R.L.Oxford (Ed.). Language learning motivation: Pathways to the new century (pp. 9-70). Hawaii: University of Hawaii Press.

Vandergrift, Larry. (2005). Relationships among Motivation Orientations, Metacognitive Awareness and Proficiency in L2 Listening. Applied Linguistics, 1, 70-89. doi:10.1093/applin/amh039, http://dx.doi.org/10.1093/applin/amh039

Weinstein, Claire E., Ernest T. Goetz \& Patricia A. Alexander. (1988). Learning and Study Strategies: Issues in Assessment, Instruction, and Evaluation. California: Academic Press, Inc.

Wen, Qiufang \& Wang, Lifei. (2003). Theoretical Research on English Learning Strategies. Xi'an: Shanxi Normal University General Publishing House.

Wen, Qiufang \& Wang, Lifei. (2004). Empirical Study on English Learning Strategies in China over the Past Twenty Years. Foreign Language and Literature, 79, 39-45.

Wen, Qiufang. (2001). Developmental patterns in motivation, beliefs and strategies of English learners in China. Foreign Language Teaching and Research, 33, 105-110.

Williams, M and Robert L. Burden. (1997). Psychology for Language Teachers: a Social Constructivist Approach. Cambridge: Cambridge University Press.

Zhang, Yaling \& Guo, Dejun. (2001). How Learning Strategic Teaching Influences Learning Motivation. Science of Psychology, 24(3), 352-353.

Table 1. Summary of Descriptive Statistic for Language Learning Motivation

\begin{tabular}{|l|c|c|c|c|c|c|}
\hline & \multirow{2}{*}{$\mathrm{M}$} & \multirow{2}{*}{$\mathrm{SD}$} & \multicolumn{2}{|c|}{$\mathrm{m} \leq 3$} & \multicolumn{2}{c|}{$\mathrm{m}>3$} \\
\cline { 4 - 7 } & & & Frequency & Percentage & Frequency & Percentage \\
\hline Intrinsic Motivation & 3.92 & .958 & 56 & $19.7 \%$ & 228 & $80.3 \%$ \\
\hline Extrinsic Motivation & 4.53 & .736 & 9 & $3.2 \%$ & 275 & $96.8 \%$ \\
\hline Personal Goals & 4.59 & .696 & 8 & $2.8 \%$ & 276 & $97.2 \%$ \\
\hline Expectancy & 3.62 & .551 & 33 & $11.6 \%$ & 251 & $88.4 \%$ \\
\hline Attitudes & 3.92 & .670 & 34 & $12 \%$ & 250 & $88 \%$ \\
\hline Anxiety & 3.04 & .953 & 148 & $52.1 \%$ & 136 & $47.9 \%$ \\
\hline Motivational Strength & 4.53 & .709 & 10 & $3.5 \%$ & 274 & $96.5 \%$ \\
\hline
\end{tabular}

Table 2. Summary of Descriptive Statistic for Language Learning Strategies

\begin{tabular}{|c|c|c|c|c|c|c|}
\hline & \multirow{2}{*}{$\mathrm{M}$} & \multirow{2}{*}{$\mathrm{SD}$} & \multicolumn{2}{|c|}{$\mathrm{m} \leq 3$} & \multicolumn{2}{|c|}{$\mathrm{m}>3$} \\
\cline { 4 - 6 } & & & Frequency & Percentage & Frequency & Percentage \\
\hline Memory Strategies & 3.98 & .616 & 20 & $7 \%$ & 264 & $93 \%$ \\
\hline Cognitive Strategies & 4.36 & .551 & 5 & $1.8 \%$ & 279 & $98.2 \%$ \\
\hline Compensation Strategies & 4.45 & .621 & 5 & $1.8 \%$ & 279 & $98.2 \%$ \\
\hline Metacognitive Strategies & 4.52 & .668 & 9 & $3.2 \%$ & 275 & $96.8 \%$ \\
\hline Affective Strategies & 4.10 & .649 & 22 & $7.7 \%$ & 262 & $92.3 \%$ \\
\hline Social Strategies & 4.33 & .696 & 12 & $4.2 \%$ & 272 & $95.8 \%$ \\
\hline Overall Strategy Use & 4.3 & .474 & 3 & $1.1 \%$ & 281 & $98.9 \%$ \\
\hline
\end{tabular}

Table 3. Case Processing Summary

\begin{tabular}{|c|c|c|c|c|c|c|}
\hline & \multicolumn{6}{|c|}{ Cases } \\
\hline & \multicolumn{2}{|c|}{ Valid } & \multicolumn{2}{|c|}{ Missing } & \multicolumn{2}{|c|}{ Total } \\
\hline & $\mathrm{N}$ & Percent & $\mathrm{N}$ & Percent & $\mathrm{N}$ & Percent \\
\hline Motivation & 284 & $100.0 \%$ & 0 & $.0 \%$ & 284 & $100.0 \%$ \\
\hline Strategy & 284 & $100.0 \%$ & 0 & $.0 \%$ & 284 & $100.0 \%$ \\
\hline
\end{tabular}


Table 4. Descriptives

\begin{tabular}{|c|c|c|c|c|}
\hline \multirow{2}{*}{ Motivation } & & Statistic & \multirow{2}{*}{$\frac{\text { Std. Error }}{.90392}$} \\
\hline & Mean & & 160.2483 & \\
\hline \multirow{25}{*}{ Strategy } & $95 \%$ Confidence & Lower Bound & 158.4691 & \\
\hline & & Upper Bound & 162.0276 & \\
\hline & $5 \%$ Trimmed Mean & & 160.5022 & \\
\hline & Median & & 160.0000 & \\
\hline & Variance & & 232.046 & \\
\hline & Std. Deviation & & 15.23306 & \\
\hline & Minimum & & 109.00 & \\
\hline & Maximum & & 203.00 & \\
\hline & Range & & 94.00 & \\
\hline & Interquartile Range & & 22.00 & \\
\hline & Skewness & & -.223 & .145 \\
\hline & Kurtosis & & .337 & .288 \\
\hline & Mean & & 202.1881 & 1.32129 \\
\hline & \multirow{2}{*}{$\begin{array}{l}95 \% \text { Confidence } \\
\text { Interval for Mean }\end{array}$} & Lower Bound & 199.5873 & \\
\hline & & Upper Bound & 204.7889 & \\
\hline & 5\% Trimmed Mean & & 202.4972 & \\
\hline & Median & & 204.0000 & \\
\hline & Variance & & 495.809 & \\
\hline & Std. Deviation & & 22.26677 & \\
\hline & Minimum & & 133.00 & \\
\hline & Maximum & & 266.00 & \\
\hline & Range & & 133.00 & \\
\hline & Interquartile Range & & 28.75 & \\
\hline & Skewness & & -.293 & .145 \\
\hline & Kurtosis & & .268 & .288 \\
\hline
\end{tabular}

Table 5. Tests of Normality

\begin{tabular}{|l|r|r|r|r|r|r|}
\hline & \multicolumn{3}{|c|}{ Kolmogorov-Smirnov(a) } & \multicolumn{3}{|c|}{ Shapiro-Wilk } \\
\cline { 2 - 7 } & Statistic & df & \multicolumn{1}{c|}{ Sig. } & Statistic & df & Sig. \\
\hline Motivation & .036 & 284 & $.200\left(^{*}\right)$ & .993 & 284 & .248 \\
Strategy & .056 & 284 & .029 & .992 & 284 & .110 \\
\hline
\end{tabular}

Table 6. Case Processing Summary

\begin{tabular}{|c|c|c|c|c|c|c|}
\hline & \multicolumn{6}{|c|}{ Cases } \\
\hline & \multicolumn{2}{|c|}{ Included } & \multicolumn{2}{|c|}{ Excluded } & \multicolumn{2}{|c|}{ Total } \\
\hline & $\mathrm{N}$ & Percent & $\mathrm{N}$ & Percent & $\mathrm{N}$ & Percent \\
\hline Motivation * Strategy & 284 & $100.0 \%$ & 0 & $.0 \%$ & 284 & $100.0 \%$ \\
\hline
\end{tabular}

Table 7.

\begin{tabular}{|lll|r|r|r|r|r|}
\hline & & & Sun of & df & Mean & Square & Sig. \\
\hline Motivation * & Between & (Combined) & 33621.113 & 107 & 314.216 & 1.726 & .001 \\
& Groups & Linearity & 13828.905 & 1 & 13828.905 & 75.945 & .000 \\
& & Deviation from & 19792.208 & 106 & 186.719 & 1.025 & .437 \\
& & Linearity & 32047.920 & 176 & 182.090 & & \\
& & & 65669.033 & 283 & & & \\
& Within Groups & & Sun of & df & Mean & F & Sig. \\
\hline
\end{tabular}


Table 8. Descriptive Statistics

\begin{tabular}{|ll|r|r|}
\hline & Mean & Std. Deviation & \multicolumn{1}{|c|}{ N } \\
\hline Motivation & 160.2483 & 15.23306 & 284 \\
Strategy & 202.1881 & 22.26677 & 284 \\
\hline
\end{tabular}

Table 9. Correlations between Learning Motivation and Language Learning Strategy Use

$* * \mathrm{P}<.01$

\begin{tabular}{|ll|r|r|}
\hline & & \multicolumn{1}{|c|}{ Motivation } & \multicolumn{2}{|c|}{ Strategy } \\
\hline Motivation & Pearson Correlation & 1 & $.459^{* *}$ \\
Strategy & Pearson Correlation & $.459^{* *}$ & 1 \\
\hline
\end{tabular}

Table 10. Correlations

\begin{tabular}{|l|l|l|l|l|l|l|l|l|}
\hline \multicolumn{2}{|l|}{} & $\begin{array}{l}\text { Memory } \\
\text { Strategies }\end{array}$ & $\begin{array}{l}\text { Cognitive } \\
\text { Strategies }\end{array}$ & $\begin{array}{l}\text { Compensation } \\
\text { Strategies }\end{array}$ & $\begin{array}{l}\text { Metacognitive } \\
\text { Strategies }\end{array}$ & $\begin{array}{l}\text { Affective } \\
\text { Strategies }\end{array}$ & $\begin{array}{l}\text { Social } \\
\text { Strategies }\end{array}$ & $\begin{array}{l}\text { Overall } \\
\text { Strategy } \\
\text { Use }\end{array}$ \\
\hline $\begin{array}{l}\text { Intrinsic } \\
\text { Motivation }\end{array}$ & $\begin{array}{l}\text { Pearson } \\
\text { Correlation }\end{array}$ & $.191(* *)$ & $.29(*)$ & $.137(*)$ & $.326(* *)$ & .115 & $.204(* *)$ & $.299(* *)$ \\
\hline $\begin{array}{l}\text { Extrinsic } \\
\text { Motivation }\end{array}$ & $\begin{array}{l}\text { Pearson } \\
\text { Correlation }\end{array}$ & $.182(* *)$ & $.144(*)$ & .089 & $.185(* *)$ & $.184(* *)$ & $.193(* *)$ & $.214(* *)$ \\
\hline $\begin{array}{l}\text { Personal } \\
\text { Goals }\end{array}$ & $\begin{array}{l}\text { Pearson } \\
\text { Correlation }\end{array}$ & $.361(* *)$ & $.342(* *)$ & $.238(* *)$ & $.391(* *)$ & $.252(* *)$ & $.328(* *)$ & $.430(* *)$ \\
\hline Expectancy & $\begin{array}{l}\text { Pearson } \\
\text { Correlation }\end{array}$ & $.272(* *)$ & $.182(* *)$ & .104 & $.162(* *)$ & $.243(* *)$ & .110 & $.240(* *)$ \\
\hline Attitudes & $\begin{array}{l}\text { Pearson } \\
\text { Correlation }\end{array}$ & $.329(* *)$ & $.376(* *)$ & $.275(* *)$ & $.322(* *)$ & $.195(* *)$ & $.263(* *)$ & $.402(* *)$ \\
\hline Anxiety & $\begin{array}{l}\text { Pearson } \\
\text { Correlation }\end{array}$ & -.075 & $-.294(* *)$ & -.098 & $-.170(* *)$ & .092 & $-.178(* *)$ & $-.185(* *)$ \\
\hline $\begin{array}{l}\text { Motivational } \\
\text { strength }\end{array}$ & $\begin{array}{l}\text { Pearson } \\
\text { Correlation }\end{array}$ & $.383(* *)$ & $.420(* *)$ & $.224(* *)$ & $.493(* *)$ & $.252(* *)$ & $.314(* *)$ & $.484(* *)$ \\
\hline Motivation & $\begin{array}{l}\text { Pearson } \\
\text { Correlation }\end{array}$ & $.341(* *)$ & $.409(* *)$ & $.224(* *)$ & $.417(* *)$ & $.355(* *)$ & $.298(* *)$ & $.459(* *)$ \\
\hline
\end{tabular}

$* * \mathrm{P}<.01, * \mathrm{P}<.05$

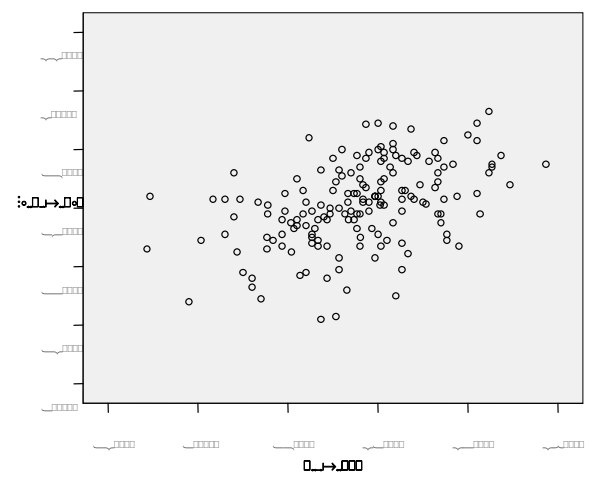

Graph 1. 